\title{
Effects of Fire Retardant Addition on the Combustion Properties of a Charring Fuel
}

\author{
Y. CHEN, A. FRENDI, S. S. TEWARI and M. SIBULKIN \\ Division of Engineering \\ Brown University \\ Providence, Rhode Island 02912, USA
}

\begin{abstract}
Results are presented which show the effect of fire retardant addition on the fuel related properties used in diffusion flame calculations. Samples of cellulose retarded with up to 3 wt. percent of sodium hydroxide were subjected to a radiant heat flux of $40 \mathrm{~kW} / \mathrm{m}^{2}$ in a special apparatus designed for this purpose. The volatile products of pyrolysis were analyzed using a gas chromatograph to determine the concentration of inert gases (carbon dioxide and water). Retardant addition was found to increase both the char yield and the production of inert gases. This results in a decrease in the fuel fraction in the pyrolysate from $69 \mathrm{wt}$. percent for pure cellulose to 35 wt. percent for retarded cellulose. The corresponding change in the stoichiometric oxygen/fuel ratio is from 1.6 for pure cellulose to a maximum of 2.3 for retarded cellulose. Retardant addition also causes a decrease in the heat of gasification (defined as the energy input to generate a unit mass of volatiles) and an increase in the heat of combustion of the combustible gases in the pyrolysate.
\end{abstract}

Keywords: (1) materials properties (2) retardants (3) heat of gasification (4) heat of combustion

\section{INTRODUCTION}

In this paper we examine the effects of a solid-phase fire retardant (sodium hydroxide) on the combustion properties of a charring fuel (cellulose). After tests with wood and commercial plastics, cellulose was chosen as an "ideal" charring material for basic studies because of its dimensional stability during combustion and the reproducibility of the results obtained. Sodium hydroxide was selected from a ranked list of retardants given by Shifazadeh et al. [1]. The method devised for preparing 
homogeneous samples containing a known amount of retardant is described in Sibulkin and Tewari [2]. Measurements of flaming combustion presented in that paper showed that sodium hydroxide is an effective retardant in the sense that addition of 0 to $3 \mathrm{wt}$. percent of $\mathrm{NaOH}$ raised the oxygen index from 0.18 to over 0.30 .

Diffusion flame theory, e.g., Sibulkin [3], can be used to predict the burning behavior of solid fuels including extinction limits. However, in order to obtain useful results from such a theory, a set of inputs must be provided which specify the material properties of the fuel and ambient gas mixture. (Experience suggests that the measurement of material properties is a more arduous task than the creation of theoretical models.) Since changes in fuel properties affect the extinction limits predicted by diffusion flame theory, one can investigate how a fire retardant acts to suppress burning by determining its effects on the combustion properties of the fuel to which it is added. This is the motivation for the work described here.

The fuel related properties which must be specified to predict burning behavior are:
$\Delta \mathrm{h}[\mathrm{comb}$ vol] $=$ heat of combustion (gas-to-gas) per unit mass of combustible volatiles
$h_{\mathrm{g}}=$ heat of gasification per unit mass of volatiles
$\mathrm{Y}_{\mathrm{FP}}=$ mass fraction of combustible volatiles (fuel) in the total volatile products of pyrolysis
$v_{\mathrm{s}}[\mathrm{comb}$ vol $]=$ stoichiometric oxygen/fuel mass ratio of the combustible volatiles

Much of the recent progress in understanding diffusion flames has been based on the use of PMMA (polymethyl methacrylate) in both calculations and experiments. Since PMMA completely volatilizes to combustible gas, its value of $\mathrm{Y}_{\mathrm{FP}}=1$. For cellulosic materials the volatile products of pyrolysis include water and carbon dioxide giving values of $\mathrm{Y}_{\mathrm{FP}}<1$. The heat of combustion which is normally measured for these charring materials is

$\Delta \mathrm{h}[\mathrm{vol}]=$ heat of combustion per unit mass of volatile, so that

$\Delta \mathrm{h}[\mathrm{vol}]=\mathrm{Y}_{\mathrm{FP}} \Delta \mathrm{h}[\mathrm{comb}$ vol $]$.

It would simplify the description of charring combustion if burning behavior depended on $\Delta h[\mathrm{vol}]$ rather than on $\Delta \mathrm{h}\left[\mathrm{comb}\right.$ vol] and $\mathrm{Y}_{\mathrm{FP}}$. Unfortunately, calculations we have made (unpublished) show that this is not the case; therefore both of these quantities must be measured. In the remainder of the paper, results are given for the effects of retardant addition on $\Delta h[\mathrm{comb} v 0 l], h_{\mathrm{g}}, \mathrm{Y}_{\mathrm{FP}}$, and $v_{\mathrm{s}}$.

\section{EXPERIMENTAL METHODS}

The apparatus used in these experiments is shown in Figs. 1 and 2. The system is designed to simulate the unsteady pyrolysis process which occurs during flaming combustion. The samples used were dry cylinders of pure and fire retarded cellulose having a diameter of $2.5 \mathrm{~cm}$ and a length of $5 \mathrm{~cm}$. The sample is placed in a horizontal position in a ceramic sample holder which sits on a top-loading electronic balance (see Fig. 1). The heat flux from a diffusion flame to the surface of the sample is simulated 


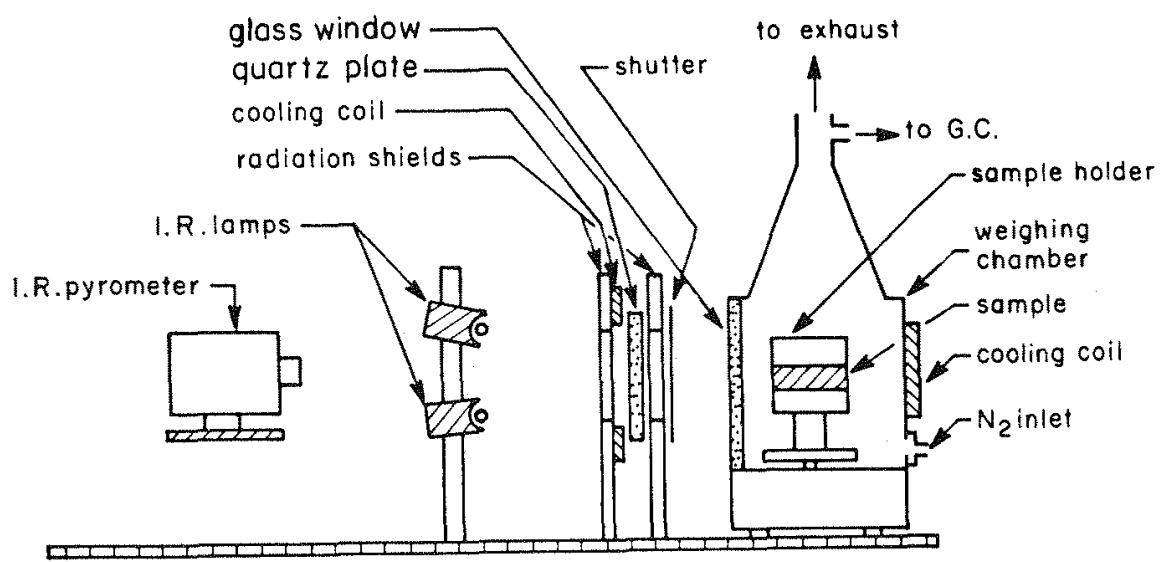

FIGURE 1. Schematic drawing showing weighing chamber and pyrolysis apparatus.

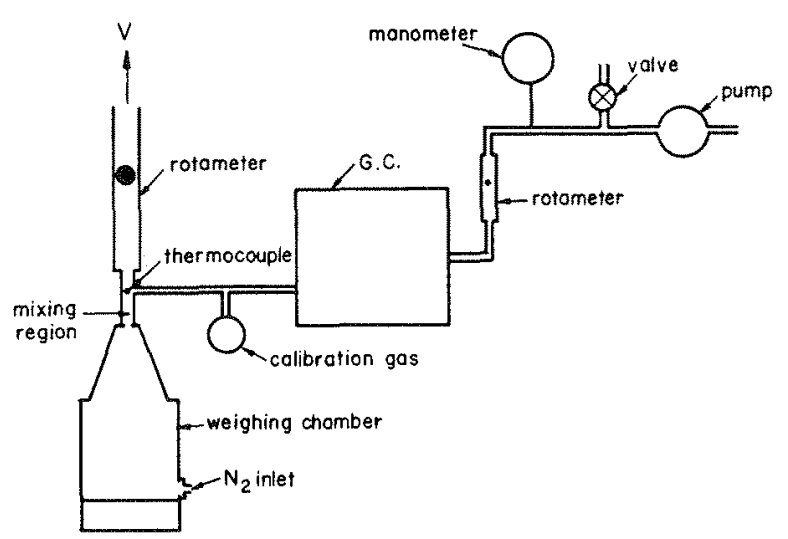

FIGURE 2. Schematic drawing showing gas analysis apparatus.

by a pair of tungsten filament, quartz-envelope infrared lamps. Pyrolysis takes place inside of a weighing chamber which is a modified glass draft shield attached to the top of the electronic balance. A nitrogen purge is used to eliminate all but a trace of oxygen from the chamber (as determined by gas chromatograph measurements). An oxygen free environment is desired to simulate flaming combustion of a solid fuel surrounded by a diffusion flame, since for such flames measurements have shown that little or no oxygen diffuses through the flame to fuel surface. This is discussed in Seshadri and Williams [4] and Chen et al. [5]. Diffusion flame calculations using finite rate chemistry also illustrate this point, for an example see Sibulkin et al. [6]. 
The portion of the apparatus used to measure the inert gases (carbon dioxide and water) produced by pyrolysis is shown in Fig. 2. The weighing chamber was purged with nitrogen before each run. During the run a reduced flow of nitrogen was used to dilute the volatiles by a factor of 100:1. The gas flow leaving the weighing chamber entered the mixing region by passing through a sharp-edged orifice plate. The relationships between the length and diameter of the mixing region and the orifice diameter were chosen to give a well mixed sample as described by Heskestad [7]. The flow rate of the diluted volatiles $V$ (which is $99 \%$ nitrogen) was measured by the rotameter directly above the mixing region. Values of $\mathrm{V}$. were calculated from the rotameter reading using the temperature measured by the thermocouple shown in the mixing region. (The measured temperatures varied from 55 to $75^{\circ} \mathrm{C}$.) This system was used to draw off a small sample (less than $1 \%$ ) of the diluted volatiles for analysis by the GC (gas chromatograph). Details about the sampling and calibration procedures are given in Chen [8].

\section{RESULTS AND DISCUSSION}

\section{Major Products of Pyrolysis}

For the purpose of obtaining combustion properties, the major products of cellulose pyrolysis are char, inert gases and combustible volatiles.

The mass fraction of char $\mathrm{Y}_{\mathrm{ch}}$ was obtained in the following manner. A thin (3 $\mathrm{mm}$ ) disk was cut from the end of a $2.5 \mathrm{~cm}$ diameter test specimen. The disk was then replaced at the end of the test specimen facing the radiant heaters (see Fig. 1) and held there by a spring-loaded clamp which is needed to maintain tension during sample shrinkage. The composite sample was irradiated for 5 to 10 minutes with a flux of 40 $\mathrm{kW} / \mathrm{m}^{2}$ which was sufficient time for the pyrolysis wave to move through the disk leaving it completely charred. Values of $Y_{c h}$ were obtained as the ratio of the weight of the sample after pyrolysis to its initial weight. (Both weight measurements were made on a dry basis.) The inert gases in the products of pyrolysis are carbon dioxide

and water. Their mass fractions were obtained from the concentrations of carbon dioxide and water vapor measured by the gas chromatograph and the flow rate measured by the rotameter (see Fig. 2). The equations used to calculate these results are given in [5]. The mass fraction of combustible volatiles is found by subtracting the inert gases from the (total) volatile products of pyrolysis; the volatile production rate is the sample mass loss rate measured in the weighing chamber.

The results of these measurements are summarized on Fig. 3 which shows how retardant addition modifies the products obtained from a unit mass of sample (cellulose plus retardant). Retardant addition causes the mass fraction of char to increase from $\mathrm{Y}_{\mathrm{ch}}=0.09$ for pure cellulose to $\mathrm{Y}_{\mathrm{ch}}=0.30$ for cellulose retarded with 3 wt. percent of $\mathrm{NaOH}\left(\mathrm{Y}_{\mathrm{R}}=0.03\right)$. This trend of increasing char production with retardant addition is a well known effect of many solid-phase fire retardants. However, the amount of char produced depends on the thermal history of the sample. For example, Shafizadeh and Sekiguchi [9] found for isothermal pyrolysis of pure cellulose that $Y_{\mathrm{ch}}$ varied from 


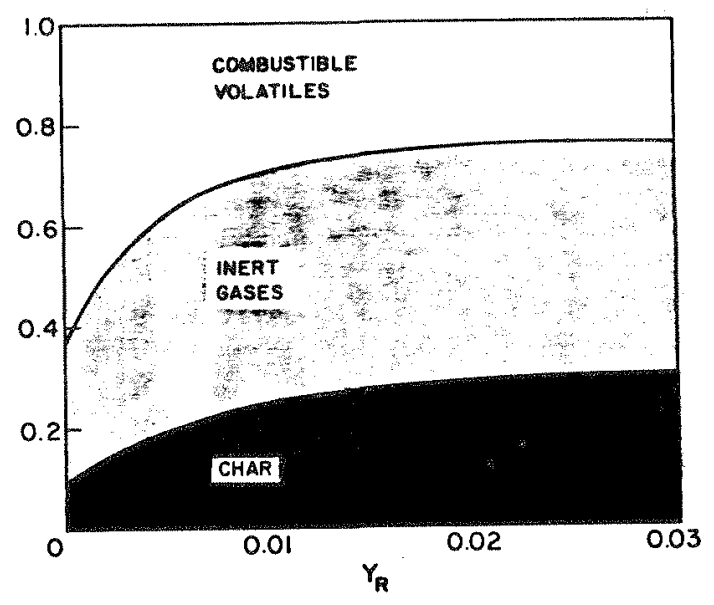

FIGURE 3. Effect of retardant concentration on major products of pyrolysis.

0.33 at $350^{\circ} \mathrm{C}$ to 0.05 at $600^{\circ} \mathrm{C}$. The mass fraction of inert gases $Y_{\text {in }}$ produced by pyrolysis is shown by the middle band on Fig. 3. These results are obtained from the concentration measurements of $\mathrm{CO}_{2}$ and $\mathrm{H}_{2} \mathrm{O}$ given in [5]. The value of $\mathrm{Y}_{\text {in }}$ increases from 0.28 for pure cellulose to 0.46 for $Y_{R}=0.03$. The mass fraction of combustion volatiles $\mathrm{Y}_{\mathrm{cv}}$ is given by

$Y_{\mathrm{cv}}=1-Y_{\mathrm{ch}}-Y_{\mathrm{in}}$

Retardant addition causes $Y_{c v}$ to decrease from0.63 for pure cellulose to 0.24 for $Y_{R}=$ 0.03 where most of the reduction occurs for 1 percent retardant addition. These results show that one of the major ways in which sodium hydroxide acts to suppress burning is by reducing the supply of combustible volatiles. In order to obtain the material properties needed for diffusion flame calculations of extinction limits, these composition results are now used to calculated values of $Y_{F P}$ and $v_{S}$.

Mass Fraction of Fuel in Pyrolysate $\mathrm{Y}_{\mathrm{FP}}$

Whereas $Y_{c v}$ is the mass fraction of combustible volatiles in the original fuel, $\mathrm{Y}_{\mathrm{FP}}$ is the mass fraction of combustible volatiles in the (total) volatiles. Therefore

$\mathrm{Y}_{\mathrm{FP}}=\mathrm{Y}_{\mathrm{cv}} /\left(1-\mathrm{Y}_{\mathrm{ch}}\right)$

and its value is plotted in Fig. 4 as a function of $Y_{R}$. Diffusion flame theory shows, as expected, that a decrease in $\mathrm{Y}_{\mathrm{FP}}$ favors extinction.

Stoichiometric Oxygen/Fuel Ratio $v_{\mathrm{S}}$ [comb vol] 
The stoichiometric ratio $v_{s}$ is defined as the mass of oxygen required for combustion of a unit mass of combustible volatiles. It is calculated from the reaction equation

$\mathrm{C}_{\mathrm{x}} \mathrm{H}_{\mathrm{y}} \mathrm{O}_{\mathrm{z}}+\left(\mathrm{v}_{\mathrm{s}} / 32\right) \mathrm{O}_{2}=\mathrm{xCO}+(\mathrm{y} / 2) \mathrm{H}_{2} \mathrm{O}$

where $\mathrm{C}_{x} \mathrm{H}_{\mathrm{y}} \mathrm{O}_{\mathrm{z}}$ represents the elemental composition of the combustible volatiles. The values of $x, y$,and $z$ were determined from the known composition of cellulose, the measured concentrations of $\mathrm{CO}_{2}$ and $\mathrm{H}_{2} \mathrm{O}$, the value of $\mathrm{Y}_{\mathrm{ch}}$, and the elemental composition of the char. The composition results and specific equations used are given in [5]. The resulting values of $v_{s}$ are shown in Fig. 4. The effect of retardant addition is to increase $v_{s}$ from 1.6 for pure cellulose to a maximum of 2.3 at $Y_{R}=0.015$ which is an increase of 40 percent. Diffusion flame theory shows that an increase in $v_{\mathrm{s}}$ favors extinction.

\section{Heat of Gasification $h_{g}$}

The heat of gasification is defined by

$h_{g} \equiv q^{\prime \prime} t^{\prime m}$

where $q^{\prime \prime}$ net is the sum of the heat flux inputs and losses at the fuel surface and $m$ " is the mass flux of gaseous products leaving the sample surface (i.e., the pyrolysis rate). The electronic balance measured the sample mass as a function of time, and the results were numerically differentiated to obtain $m^{\prime \prime}(t)$. The net heat flux is found from

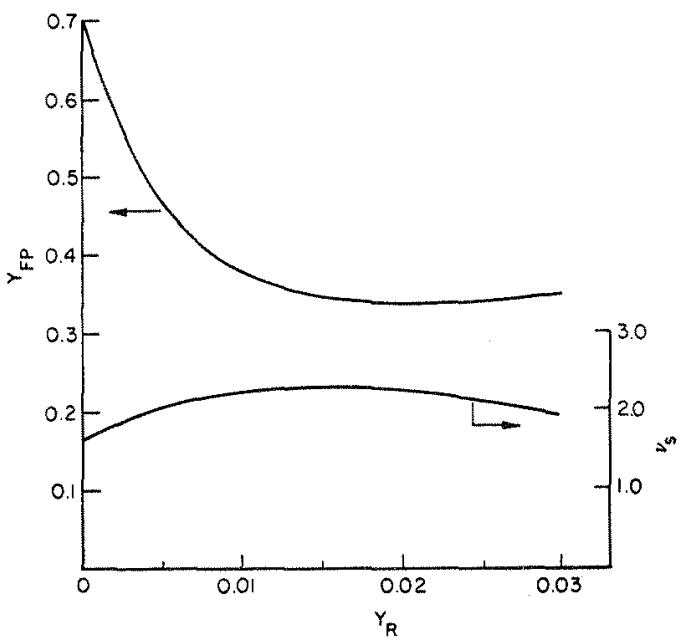

FIGURE 4. Variation of fuel fraction in pyrolysate and stoichiometric ratio. 
$\mathrm{q}_{\text {net }}^{\prime \prime}=\varepsilon \mathrm{q}_{\mathrm{ex}}^{\prime \prime}-\varepsilon \sigma\left[\mathrm{T}_{\mathrm{w}}^{4}-\mathrm{T}_{\infty}^{4}\right]-\mathrm{q}_{\text {conv }}^{\prime \prime}$

by the following procedures. The value of the external heat flux $\mathrm{q}_{\text {ex }}^{\prime \prime}$ which is incident on the sample surface was calibrated against the power input to the I.R. lamps before and after each run by placing a water-cooled radiation flux gage at the sample location. The surface temperature $T_{w}(t)$ was obtained from a calibration curve of the voltage output of the I.R. pyrometer against surface temperature. The convective heat loss $\mathrm{q}^{\prime \prime}$ conv could not be measured. Its value was calculated from heat transfer theory for free-convection from a vertical surface with blowing using the measured values of $T_{w}$ and $\mathrm{m}^{\prime \prime}$.

The effect of retardant addition on the heat of gasification $h_{g}$ calculated from Eqs. (4) and (5) is shown in Fig. 5. The combination of retardant effects discussed above reduces $h_{g}$ by a factor of 2 below its value for pure cellulose with most of the reduction taking place for 1 percent retardant addition. Based upon diffusion flame theory, this reduction in $\mathrm{h}_{\mathrm{g}}$ opposes extinction since less energy is needed to pyrolyse a unit mass of fuel.

\section{Heat of Combustion $\Delta \mathrm{h}[\mathrm{comb}$ vol]}

The burning characteristics of solid fuels depends upon the heat of combustion of the volatile products of pyrolysis. For use in diffusion flame models the specific property needed is the heat of combustion (on a gas-to-gas basis) of the combustible products of pyrolysis. In this work a subtraction method introduced by Yeh et al. [10]

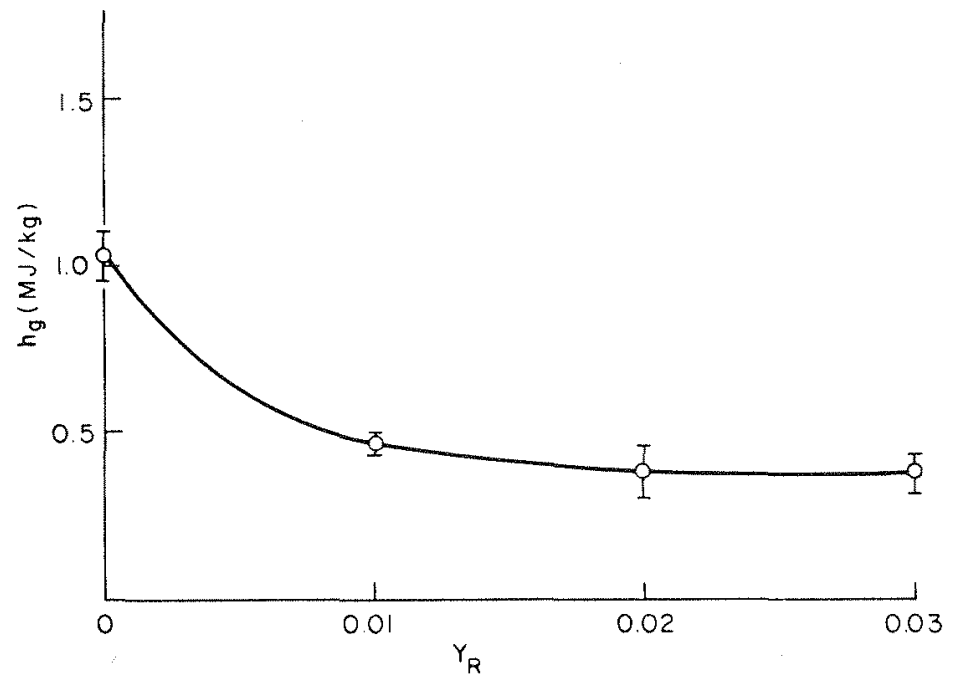

FIGURE 5. Effect of retardant concentration on heat of gasification. 
was used. In the subtraction method the heat of combustion (per unit mass of volatiles) is calculated from

$\Delta \mathrm{h}[\mathrm{vol}]=\Delta \mathrm{h}[$ cell $+\mathrm{ret}]-\mathrm{Y}_{\mathrm{ch}} \Delta \mathrm{h}[\mathrm{char}] /\left(1-\mathrm{Y}_{\mathrm{ch}}\right)$

where $\Delta \mathrm{h}$ [cell + ret] is the heat of combustion of the original material, cellulose plus retardant, measured in a bomb calorimeter, and $\Delta h$ [char] is the heat of combustion of the char from that material obtained by a separate bomb calorimeter measurement. The value for the combustible volatiles is then found from

$\Delta \mathrm{h}[\mathrm{comb}$ vol $]=\Delta \mathrm{h}[\mathrm{vol}] / \mathrm{Y}_{\mathrm{FP}}$

where the measurements of $Y_{c h}$ and $Y_{F P}$ have been described above. The bomb calorimeter measurements were carried out at $25^{\circ} \mathrm{C}$. The corresponding results on a gas-to-gas basis were obtained by correcting the heats of combustion for both cellulose and char to $400^{\circ} \mathrm{C}$ as described in Susott et al. [11].

The effects of retardant addition are shown in Fig. 6. For the (total) volatiles, retardant addition decreases the heat of combustion by up to 30 percent. This decrease in $\Delta \mathrm{h}[\mathrm{vol}]$ is primarily due to the increase in the inert gas fraction of the volatiles as $\mathrm{Y}_{\mathrm{R}}$ increases. For the combustible volatiles, retardant addition increases the heat of combustion by up to 35 percent. This increase in $\Delta \mathrm{h}[\mathrm{comb}$ vol] is due to an increase in

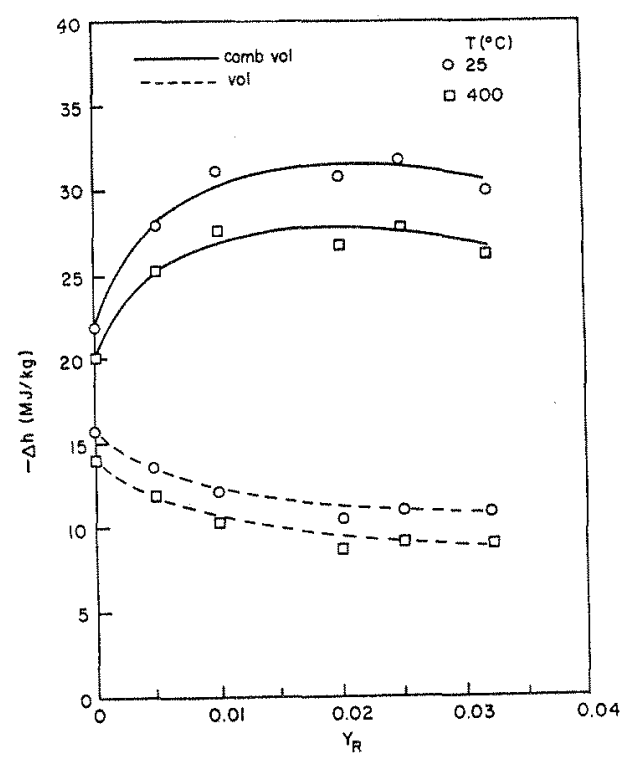

FIGURE 6. Heat of combustion of volatiles and of combustible volatiles. 
the carbon content of the combustible volatiles as $\mathrm{Y}_{\mathrm{R}}$ increases. Based upon diffusion flame theory this increase in $\Delta \mathrm{h}[\mathrm{comb} \mathrm{vol}]$ is a retardant effect which opposes extinction.

\section{CONCLUSIONS}

The results of this investigation are summarized in Table 1 which shows the effects of retardant addition on the combustion properties of cellulose. (Values of $T_{W}$ are also tabulated.) Table 1 shows that most of the changes take place for a retardant concentration $\mathrm{Y}_{\mathrm{R}}$ less than 0.02 . Some of these changes tend to promote flaming combustion, i.e., the increase in the heat of combustion $-\Delta h$ and the decrease in the heat of gasification $\mathrm{h}_{\mathrm{g}}$. However, as noted in the Introduction, sodium hydroxide is an effective fire retardant. Therefore the retardant action of sodium hydroxide must be due to its effects on the remaining properties. The changes which oppose flaming combustion are the decrease in the fuel fraction in the pyrolysate $\mathrm{Y}_{\mathrm{FP}}$ and the increase in the stoichiometric ratio $v_{s}$. Both of these results are closely related to the increases in inert gas production with retardant addition. The increase in $T_{w}$ with retardant addition also opposed flaming combustion since it increases the radiative heat loss from the fuel surface.

\section{ACKNOWLEDGEMENT}

This work was supported by the Center for Fire Research of the National Bureau of Standards under Grants NB60NANB6D0629 and 60NAND8D0851.

Table 1. Material Properties for use in Diffusion Flame Calculations a

\begin{tabular}{cccccc}
$\mathrm{Y}_{\mathrm{R}}$ & $\begin{array}{c}-\Delta \mathrm{h}^{\mathrm{b}} \\
(\mathrm{MJ} / \mathrm{kg})\end{array}$ & $\begin{array}{c}\mathrm{h}_{\mathrm{g}} \\
(\mathrm{MJ} / \mathrm{kg})\end{array}$ & $\mathrm{Y}_{\mathrm{FP}}$ & $v \mathrm{~s}^{\mathrm{b}}$ & $\begin{array}{c}\mathrm{T}_{\mathrm{w}} \\
(\mathrm{K})\end{array}$ \\
\cline { 5 - 6 } & & - & - & - & - \\
0.005 & 20 & 1.01 & 0.69 & 1.6 & 826 \\
0.010 & 26 & 0.61 & 0.47 & 1.9 & 844 \\
0.015 & 28 & 0.46 & 0.38 & 2.2 & 854 \\
0.020 & 27 & 0.40 & 0.35 & 2.3 & 856 \\
0.025 & 28 & 0.38 & 0.34 & 2.2 & 857 \\
0.030 & 26 & 0.38 & 0.34 & 2.1 & 857 \\
\cline { 5 - 6 } & 28 & 0.37 & 0.35 & 2.0 & 857
\end{tabular}

a Values for $\mathrm{q}^{\prime \prime}{ }_{\mathrm{ab}}=40 \mathrm{~kW} / \mathrm{m}^{2}$ at $\mathrm{t}=180 \mathrm{~s}$. ${ }^{\mathrm{b}}$ For combustible volatiles. 
Additional support was provided A. Frendi by a graduate fellowship from the Republic of Algeria.

\section{REFERENCES}

1. Shafizadeh, F., Chin, P-S. and De Groot, W.F., "Mechanistic evaluation of flame retardants." Fire Retardant Chemistry 2:195-203, 1975.

2. Sibulkin, M. and Tewari, S.S., "Measurements of flaming combustion of pure and fire retarded cellulose." Combustion and Flame 59:31-42, 1985.

3. Sibulkin, M., "Free convection diffusion flames from burning solid fuels. Prog. Energy Combust. Sci. 14:195-212, 1988.

4. Seshadri, K. and Williams, F.A., "Structure and extinction of counterflow flames above condensed fuels." J. Polymer Sci: Polymer Chem. Ed. 16:1775-1778, 1978.

5. Chen, Y., Frendi, A., Tewari, S.S. and Sibulkin, M., "Combustion properties of pure and fire retarded cellulose." Combustion and Flame, (in press).

6. Sibulkin, M., Kulkarni, A.K. and Annamalai, K. "Burning on a vertical fuel surface with finite chemical reaction rate." Combustion and Flame 44:187-199, 1982.

7. Heskestad, G., "A fire products collector for calorimetry into the MW range." Factory Mutual Research Report J.I. OC2E1.RA, Norwood, MA., pp. 1-3, 1981.

8. Chen,Y., "An experimental study of the pyrolysis of pure and fire retarded cellulose." Ph.D. Thesis, Brown University, Providence, RI, 1989.

9. Shafizadeh, F. and Sekiguchi, Y., "Oxidation of chars during smoldering combustion of cellulosic materials." Combustion and Flame 55:171-179, 1984.

10. Yeh, K-N., Birky, M.M. and Huggett, C., "Calorimetric study of flammable fabrics. II. Analysis of flame retardant-treated cotton." I. Appl. Polymer Sci. $17: 225-268,1973$.

11. Susott, R.A., De Groot, W.F. and Shafizadeh, F., "Heat content of natural fuels." J. Fire Flammability $6: 311-325,1975$. 